\title{
Glycosylated Haemoglobins and the Oxygen Affinity of Whole Blood
}

\author{
M.Samaja ${ }^{1}$, D. Melotti ${ }^{1}$, A.Carenini² and G.Pozza ${ }^{2}$ \\ ${ }^{1}$ Centro di Fisiologia del Lavoro Muscolare del C. N. R., and ${ }^{2}$ Istituto di Clinica Medica, Ospedale San Raffaele, Milan, Italy
}

\begin{abstract}
Summary. The $\mathrm{pO}_{2}$ at which haemoglobin is half-saturated with oxygen (p50) was determined at fixed $\mathrm{pCO}_{2}(45 \mathrm{mmHg})$ and without altering the resulting $\mathrm{pH}$ and the level of organic phosphates in heparinized whole blood samples from 26 diabetic patients and 24 normal subjects of both sexes. Diabetic blood p50 was higher $(29.79 \pm 1.68$ versus $28.26 \pm$ $1.16 \mathrm{mmHg}, p<0.001$ ) and with a higher 2,3-diphosphoglyceric acid/haemoglobin molar ratio $(1.04 \pm 0.15$ versus $0.86 \pm$ $0.10, p<0.001$ ). The $\mathrm{pH}$ at a $\mathrm{pCO}_{2}$ of $45 \mathrm{mmHg}$ was the same in the two groups. The observed $\mathrm{p} 50$ values were compared
\end{abstract}

with those obtained after normalization in respect to $\mathrm{pH}$ and the level of 2,3-diphosphoglyceric acid. We conclude that glycosylated haemoglobins, known to have an increased affinity for oxygen when purified and in diluted solutions, do not play a significant role in the oxygen affinity pattern of diabetics at the concentrations normally found in vivo.

Key words: Glycosylated haemoglobins, $\mathrm{HbA}_{1 \mathrm{c}}$, blood oxygen affinity, 2,3-diphosphoglyceric acid, blood gases.
Glycosylated haemoglobins $\left(\mathrm{HbA}_{1}\right)$, of which the most abundant fraction is $\mathrm{HbA}_{1 \mathrm{c}}$, are known to occur at higher levels in diabetic than in normal blood [1], and thus to be an index of diabetic control [2]. Purified and diluted solutions of $\mathrm{HbA}_{1 \mathrm{c}}$, in presence of organic phosphates at $\mathrm{pH} 7.0$ and $20^{\circ} \mathrm{C}$, show a higher affinity for oxygen in respect to normal haemoglobin [3]. Many authors [2, 4-6] have extrapolated these results, hypothesizing that in diabetic blood in vivo there is a higher oxygen affinity compared with normal blood under the same conditions. Direct experimental support for this hypothesis is, however, ambiguous, mainly because the other factors known to affect haemoglobin oxygen affinity (hydrogen ions, carbon dioxide, and organic phosphates) interfere with the postulated effect of $\mathrm{HbA}_{1 \mathrm{c}}$, which is therefore not easily detectable $[7,8]$.

The purpose of this investigation was to evaluate the effect of glycosylated haemoglobins on the regulation of the oxygen affinity in whole blood from diabetic subjects. This has been made possible by a new method for determining the $\mathrm{p} 50$ (the $\mathrm{pO}_{2}$ at which haemoglobin is half-saturated with oxygen) with an accuracy of \pm $0.3 \mathrm{mmHg}$ [9]. The equations reported here and in the literature [9] for calculating the normal human blood p50 from known concentrations of hydrogen ions, carbon dioxide, and 2,3-diphosphoglyceric acid (2,3-DPG) allowed the normalization of the observed $\mathrm{p} 50$ values.

\section{Patients and Methods}

\section{Patients}

Twenty-six diabetics (12 males and 14 females) on insulin treatment were the subjects of this investigation. The patients were admitted to hospital for assessment of their glycaemic control. Smokers, ketotic and acidotic patients, patients with abnormal haemoglobins, methaemoglobinemia, renal failure, other diseases besides diabetes mellitus, and patients with regular drug intake other than insulin were excluded from the present study to avoid possible interferences by unidentified factors during evaluation of the oxygen affinity state.

The control group was 24 normal, healthy, non-smoking volunteers (13 males and 11 females) with no family history of diabetes. Informed consent was obtained from all subjects before venepuncture.

\section{Methods}

One $\mathrm{ml}$ of blood was withdrawn from the antecubital vein $3-5 \mathrm{~h}$ after insulin administration (in the case of diabetic patients). Blood was treated with lithium-heparin and immediately placed in an ice-bath. All samples were analyzed within $2 \mathrm{~h}$ of venepuncture.

An aliquot of the sample $(0.4 \mathrm{ml})$ was tonometered in a closed flask with known $\mathrm{pO}_{2}$, at a fixed $\mathrm{pCO}_{2}$ of $45 \mathrm{mmHg}$ at $37^{\circ} \mathrm{C}$, without addition of acids or bases. The haemoglobin saturation for oxygen and the $\mathrm{p} 50$ were measured as previously described [9]. The $\mathrm{p} 50$ value was normalized with respect to $\mathrm{pH}, \mathrm{pCO}_{2}$ and the [2,3-DPG]/[Hb] molar ratio using the following equations:

$\log {\mathrm{p} 50_{p H} 7.0}=\left(-0.69117 \times 10^{-3} \times \mathrm{pCO}_{2}+0.3365\right) \times \mathrm{G}$

$+\left(0.3598 \times 10^{-3} \times \mathrm{pCO}_{2}+1.599\right)$ 
Table 1. Oxygen affinity of blood from normal subjects and diabetic patients at $37^{\circ} \mathrm{C}, \mathrm{pCO}_{2}=45 \mathrm{mmHg}$, unaltered $\mathrm{pH}$ and level of $2,3-\mathrm{DPG}$

\begin{tabular}{|c|c|c|c|c|c|c|c|c|}
\hline \multirow{3}{*}{$\begin{array}{l}\text { Age (years) } \\
\text { Duration of diabetes (years) }\end{array}$} & \multicolumn{2}{|c|}{$\begin{array}{l}\text { Normal subjects } \\
(n=24)\end{array}$} & $\begin{array}{l}\text { Diabetic patients } \\
\text { (all) } \\
(n=26)\end{array}$ & \multirow{3}{*}{$\begin{array}{c}p^{\alpha} \\
-\end{array}$} & \multicolumn{2}{|c|}{$\begin{array}{l}\text { Diabetic patients } \\
\text { (present age } \\
<30 \text { years) } \\
(n=8)\end{array}$} & \multicolumn{2}{|c|}{$\begin{array}{l}\text { Diabetic patients } \\
\text { (present age } \\
>30 \text { years) } \\
(n=18)\end{array}$} \\
\hline & 25.7 & \pm 3.5 & $48.1 \pm 25.8$ & & 23.6 & \pm 7.5 & 57.7 & \pm 12.2 \\
\hline & & - & $9.3 \pm 8.2$ & & 1.8 & +1.3 & 12.3 & \pm 8.2 \\
\hline $\mathrm{HbA}_{1}(\%)$ & 7.25 & \pm 1.12 & $11.75 \pm 2.40$ & $<0.001$ & 12.18 & \pm 2.64 & 11.58 & \pm 2.36 \\
\hline$[2,3-\mathrm{DPG}] /[\mathrm{Hb}](\mathrm{mol} / \mathrm{mol})$ & 0.86 & \pm 0.10 & $1.04 \pm 0.15$ & $<0.001$ & 1.03 & \pm 0.06 & 1.05 & \pm 0.16 \\
\hline Normalized p50 (mmHg) & 28.87 & \pm 1.25 & $30.96 \pm 1.70$ & $<0.001$ & 31.21 & \pm 0.88 & 30.90 & \pm 1.96 \\
\hline$\Delta \mathrm{p} 50^{\mathrm{b}}$ & 0.61 & \pm 0.80 & $1.17 \pm 1.23$ & NS & 1.18 & \pm 1.27 & 1.10 & \pm 1.30 \\
\hline Hill's factor ${ }^{c}$ & 2.68 & \pm 0.07 & $2.66 \pm 0.08$ & NS & & - & & - \\
\hline $\mathrm{MCHC}(\mathrm{g} / \mathrm{dl})^{\mathrm{d}}$ & 35.1 & \pm 2.8 & $35.2 \pm 2.5$ & NS & & - & & - \\
\hline
\end{tabular}

Results are expressed as mean $\pm \mathrm{SD}$

${ }^{a} p$ refers to the comparison of normal subjects versus all diabetic patients. NS $=$ not significant $(p>0.1)$

b Expressed as (normalized p50) - (experimental p50)

c Calculated on eight normal and 12 diabetic samples

d Mean corpuscular haemoglobin concentration, calculated on eight normal and 21 diabetic samples

$\log \mathrm{p} 50_{\mathrm{pH}} 7.6=\left(-0.138 \times 10^{-2} \times \mathrm{pCO}_{2}+0.3607\right) \times \mathrm{G}$

$+\left(0.9089 \times 10^{-3} \times \mathrm{pCO}_{2}+1.360\right)$

$\left.\log \mathrm{p} 50_{p H}=\frac{\left\{(\mathrm{pH}-7.0) \times\left(\log \mathrm{p} 50_{p H} 7.6-\log \mathrm{p} 50_{p H} 7.0\right)\right\}}{0.6}\right\}$

$+\log \mathrm{p} 50 p H 7.0$

where $\left.\mathrm{G}=\log _{10}[2,3-\mathrm{DPG}] / \mathrm{LHb}\right]$.

For the assay of $\mathrm{HbA}_{1}$, the haemolysate was obtained by a fivefold dilution of the blood into the haemolyzing agent $(0.33 \%$ polyoxyethylene ether), and the fast haemoglobin fractions were separated using kits from Bio-Rad Laboratories, Richmond, California [10]. The total haemoglobin concentration was determined by the standard method of Drabkin [11]. The concentration of 2,3-DPG was measured in the blood sample simultaneously with determination of $\mathrm{p} 50$, using kits from Boehringer Biochemia, Milan, Italy, and was expressed as the molar ratio of 2,3-DPG to haemoglobin tetramer. The mean corpuscular haemoglobin concentration was measured using an S-Plus Coulter counter (Coulter Electronics, Hialeah, FL, USA). The level of carbonmonoxyhaemoglobin and of methaemoglobin were determined by a microblood analyzer (Carlo Erba Strumentazione, Milan, Italy).

The Hill's factor, $\mathrm{n}$, was determined in eight normal and 12 diabetic samples of both sexes [12]. The oxygen saturation was measured at three different oxygen tensions, one near the p 50 , and the other two a few $\mathrm{mmHg}$ above and below the $\mathrm{p} 50$. The factor was calculated as the slope of the regression line when the experimental data were plotted as proposed by Hill.

For the statistical analysis of the results, Student's t-test for paired and unpaired data, linear regression and correlation coefficients were applied as appropriate.

\section{Results}

The results are summarized in Table 1 . Few differences were found between the two age classes of diabetic patients. As expected, the level of $\mathrm{HbA}_{1}$ was higher in diabetic patients than in control subjects [1]. The p50, measured at unaltered $\mathrm{pH}$ and 2,3-DPG level, was higher in diabetics. Blood $\mathrm{pH}$ after the tonometry was the same in the two groups. The level of 2,3-DPG and the normalized $\mathrm{p} 50$ values were higher in diabetics. The difference $(\Delta \mathrm{p} 50)$ between the normalized p50 and the experimental $\mathrm{p} 50$, represents the functional difference between the blood sample under investigation and the reference normal blood, and was similar in both groups. The Hill's factor and the mean corpuscular haemoglobin concentration, which is a factor possibly affecting the oxygen affinity of blood [13], were the same in both groups. The levels of carbonmonoxyhaemoglobin and of methaemoglobin never exceeded $2 \%$ and $1 \%$ respectively.

A systematic difference was found between males and females. The [2,3-DPG]/[Hb] ratio was always higher in females $(0.92 \pm 0.10$ versus $0.84 \pm 0.07$, in normal subjects, $p<0.01$; and $1.07 \pm 0.15$ versus 1.00 \pm 0.10 , in diabetic patients, $p<0.10$ ). The increase of 2,3-DPG level corresponds to an increase of their p50, and $\Delta \mathrm{p} 50$ was similar for females and males $(0.61 \pm$ $1.13 \mathrm{mmHg}$ versus $0.67 \pm 0.51 \mathrm{mmHg}$ among normal subjects; and $0.97 \pm 1.46 \mathrm{mmHg}$ versus $1.34 \pm$ $0.96 \mathrm{mmHg}$ among diabetic patients).

Eight of the diabetic patients were newly diagnosed. Their [2,3-DPG] $/[\mathrm{Hb}]$ ratio was $1.00 \pm 0.06$, and their $\Delta$ p50 $1.09 \pm 1.26 \mathrm{mmHg}$. The values of p50 and of $\Delta \mathrm{p} 50$ were not correlated with body weight or the duration of diabetes.

The level of 2,3-DPG was significantly correlated with the level of $\mathrm{HbA}_{1}([2,3-\mathrm{DPG}] /[\mathrm{Hb}]=0.70+0.027$ $\times \mathrm{HbA}_{1}, r=0.51, p<0.001, n=50$ ). Consequently the p50 value was also correlated with the level of $\mathrm{HbA}_{1}$ $\left(\mathrm{p} 50=26.42+0.277 \times \mathrm{HbA}_{1}, \mathrm{r}=0.48, p<0.001, n=\right.$ 50). In contrast, there was a very weak correlation of $\Delta \mathrm{p} 50$ with $\mathrm{HbA}_{1}\left(\Delta \mathrm{p} 50=0.04+0.088 \times \mathrm{HbA}_{1}, r=\right.$ $0.25, p<0.1, n=50)$. 


\section{Discussion}

The $\mathrm{p} 50$ is a useful parameter in defining the position of the oxyhaemoglobin dissociation curve. Hydrogen ions, carbon dioxide, and 2,3-DPG are its principal effectors [9]. In diabetic patients, the value of blood $\mathrm{pH}$ and $\mathrm{pCO}_{2}$ depend on the value of the base excess, following the acid-base laws, but there are conflicting data in the literature about the levels of 2,3-DPG [14]. Arturson et al. [7] and Ditzel et al. [8] reported that the concentration of 2,3-DPG is increased in diabetics, and that the expected increase of $\mathrm{p} 50$ is compensated by the presence of larger amounts of $\mathrm{HbA}_{1}$ and of $\mathrm{HbA}_{1 \mathrm{c}}$. These investigations were complicated by the difficulty in normalizing $\mathrm{p} 50$ with respect to $\mathrm{pH}, \mathrm{pCO}_{2}$, and the level of 2,3DPG.

In the present study, the $\mathrm{p} 50$ was measured in whole blood by a previously described method, with control of the main regulating factors [9]. The equations $(1-3)$ were used to normalize the experimental data to the desired $\mathrm{pH}, \mathrm{pCO}_{2}$, and 2,3-DPG level. Therefore it was possible to state if an apparently abnormal p50 could be explained by abnormalities of the base excess, the [2,3$\mathrm{DPG}] /[\mathrm{Hb}]$ ratio, or whether other unidentified factors (such as variant haemoglobins) might play a role. As the second possibility, the difference between the normalized $\mathrm{p} 50$ and the experimental $\mathrm{p} 50, \Delta \mathrm{p} 50$, might represent an index of functional abnormality of the blood sample under investigation.

The interaction coefficients of $\mathrm{HbA}_{1}$ with the considered allosteric factors are presently unknown. However, the Hill's factor, the determination of which is independent of any assumption, is the same in both groups, implying that the haemoglobin molecule is functionally equivalent in the two groups of subjects. We assumed therefore that the reported equations represent the situation in the blood of diabetic patients.

Table 1 shows that $\Delta \mathrm{p} 50$ is similar in the two groups, suggesting that factors other than hydrogen ions, carbon dioxide, and 2,3-DPG, such as $\mathrm{HbA}_{1}$, do not play any significant role in the oxygen affinity regulation in diabetics. Patients with $\mathrm{HbA}_{1}$ levels above $15-16 \%$ could not be included in this investigation because of the possibility that limitations in their diet and physical activity lead to an altered p50 per se. A few samples with $\mathrm{HbA}_{1}>16 \%$ (not included in Table 1 because of the exclusions stated) do however show almost complete overlapping with the data in Table 1 . The subdivision of diabetics in two age classes was necessary to assess the validity of the control group.

Of other possible factors, the level of carbonmonoxyhaemoglobin and of methaemoglobin must be ruled out because they are low. In addition, the mean corpuscular haemoglobin concentration was similar in the two groups.

Ditzel et al. [15] observed that the level of 2,3-DPG may fluctuate consistently during the day depending on many factors, such as insulin administration and per- haps physical activity. In order to reduce this uncertainty to a minimum, we studied only hospitalized nonacidotic and non-ketotic patients. In addition, blood samples were taken 3 to 5 hours after the daily insulin dose, in order to reduce any possible effect on the red blood cell metabolic processes, and thus on the level of 2,3-DPG.

The increased oxygen affinity of $\mathrm{HbA}_{1 \mathrm{c}}$ has been shown in purified haemoglobin solutions $([\mathrm{Hb}]=$ $0.05 \mathrm{mmol} / \mathrm{l}, \mathrm{pH} 7.0, \mathrm{t}=20^{\circ} \mathrm{C}$, presence of inositol. hexaphosphate, low ionic strength) [3], and has been attributed to the low reactivity of this haemoglobin derivative with organic phosphates [16]. This pattern does not occur under the intracellular conditions imposed by this study $\left([\mathrm{Hb}]=20 \mathrm{mmol} / 1, \mathrm{pH} 7.2, \mathrm{t}=37^{\circ} \mathrm{C}\right.$, high ionic strength, presence of divalent cations and of organic salts). It is possible that spontaneous and rapid dimerization of haemoglobin at low concentrations changes its equilibrium with oxygen, thus altering the physiological conditions under which haemoglobin exists in whole blood [17].

It has been suggested that long-term diabetic complications are mainly caused by tissue hypoxia due to the higher oxygen affinity of glycosylated haemoglobins [8]. Our results suggest that the slightly, although significantly, higher p50 in diabetics may be of little physiological importance, and is however independent of the state of glycosylation of haemoglobin. In addition, there were no significant differences between newly discovered diabetics, and diabetic patients with several years duration of illness.

\section{References}

1. Trivelli LA, Ranney HM, Lai H-T (1971) Hemoglobin components in patients with diabetes mellitus. $N$ Engl J Med 284: 353-357

2. Bunn HF, Gabbay KH, Gallop PM (1978) The glycosylation of hemoglobin: relevance to diabetes mellitus. Science 200:21-27

3. McDonald MJ, Bleichmann M, Bunn HF, Noble RW (1979) Functional properties of the glycosylated minor components of human adult hemoglobin. J Biol Chem 254: 702-707

4. Ditzel J, Andersen H, Daugaard Peters N (1973) Increased haemoglobin $A_{1 c}$ and 2,3-diphosphoglycerate in diabetes and their effect on red cell oxygen release capacity. Lancet 2: 1034 (Letter)

5. Ditzel J, Nielsen NV, Kjaergaard J-J (1979) Hemoglobin $A_{1 c}$ and red cell oxygen release capacity in relational to early retinal changes in newly discovered overt and chemical diabetics. Metabolism 28 (Suppl 1): 440-447

6. Ditzel J (1979) Changes in red cell oxygen release capacity in diabetes mellitus. Fed Proc 38: 2484-2488

7. Arturson G, Garby L, Robert M, Zaar B (1974) Oxygen affinity of whole blood in vivo and under standard conditions in subjects with diabetes mellitus. Scand J Clin Lab Invest 34: 19-22

8. Ditzel J (1980) Affinity hypoxia as a pathogenetic factor of microangiopathy with particular reference to diabetic retinopathy. Acta Endocrinol 94: 39-55

9. Samaja M, Mosca A, Luzzana M, Rossi-Bernardi L, and Winslow RM (1981) Equations and nomogram for the relationship of human blood p50 with 2,3-DPG, $\mathrm{CO}_{2}$, and $\mathrm{H}^{+}$. Clin Chem 27: 1856-1861 
10. Mosca A, Carenini A, Samaja M, Saibene V (1980) Temperature control in assay of glycosylated hemoglobins. Clin Chem 26:1106 (Letter)

11. Drabkin DL (1950) Spectroscopy, photometry, and spectrophotometry. In: Glaser O (ed) Medical physics. Year Book Publishing, Chicago, IL p 1039-1088

12. Hill AV (1910) The possible effect of aggregation of the molecules of haemoglobin on its dissociation curve. J Physiol (Lond) 40: 4-7

13. Bellingham AJ, Detter JC, Lenfant C (1971) Regulatory mechanism of hemoglobin oxygen affinity in acidosis and alkalosis. J Clin Invest 50: 700-706

14. Ditzel J, Jaeger P, Standl E (1978) An adverse effect of insulin on the oxygen release capacity of red blood cells in nonacidotic diabetics. Metabolism 27: 927-934

15. Ditzel J, Standl E (1975) The problem of tissue oxygenation in diabetes mellitus. II: Evidence of disordered oxygen release from the erythrocytes of diabetics in various conditions of metabolic control. Acta Med Scand (Suppl) 578: 49-58
16. Bunn HF, Briehl RW (1970) The interaction of 2,3-diphosphoglycerate with various human hemoglobins. J Clin Invest 49: 1088-1095

17. Ip SHC, Johnson ML, Ackers GK (1976) Kinetics of deoxyhemoglobin subunit dissociation determined by haptoglobin binding: estimation of the equilibrium constant from forward and reverse rates. Biochemistry 15:654-659

Received: 10 August 1981

and in revised form: 21 June 1982

Dr. Michele Samaja

Cattedra di Chimica Biologica

Ospedale San Raffaele

via Olgettina 60

I-20132 Milano

Italy 